\title{
Residual stress development during nitriding of steels
}

\author{
Sebastien Jegou ${ }^{1, a}$, Laurent Barrallier ${ }^{1, b}$, Régis Kubler ${ }^{1, c}$ \\ ${ }^{1}$ Arts \& Métiers ParisTech, MécaSurf Laboratory, 2 cours des Arts et Métiers, 13617 Aix-en-Provence, \\ France \\ asebastien.jegou@ensam.eu, ${ }^{\mathrm{b}}$ laurent.barrallier@ensam.eu, ${ }^{\mathrm{c}}$ regis.kubler@ensam.eu
}

Keywords: nitriding, precipitation, residual stress, modelling

\begin{abstract}
Nitriding is a well-established thermochemical surface treatment of carbon micro-alloyed steels aiming enhancing surface properties such as fatigue, wear and corrosion resistances. The idea is taking benefits from the high hardening level due to a fine nitride precipitation and also the compressive residual stress state. Due to some complex interactions of phenomena during nitriding, the last has not been completely explained yet. When interest is focused on stress depth gradient and time evolution, difficulties find origins in pronounced heterogeneities whether it is the chemical gradient due to nitrogen diffusion, the resulting gradient of microstructure or the gradient of volumetric misfits. Relaxation of residual stresses is so usually described using a thermally controlled creep phenomenon due to the couple of diffusion and stress, but depend on phenomenological descriptions. A key point is also disregard that is the diffusion of carbon and its redistribution across the nitrided surface during the treatment. Based on experimental characterizations of model carbon iron-based alloys, the role of phase transformations, especially carbides, is explored in order to give better understandings of the residual stress development during nitriding.
\end{abstract}

\section{Introduction}

Residual stress in nitrided iron-based alloys arise through the generation of chemically induced misfits according to nitrogen addition and the precipitation of fine $\mathrm{MN}$ nitrides $(\mathrm{M}=\mathrm{Cr}, \mathrm{V}$, Mo...) [1]. During nitriding, a gradient of compressive residual stress develops and finds its origin through the diffusion of nitrogen. The resulting gradient of microstructure involves a gradient of volumetric eigenstrains according to the volume change accompanying the precipitation, thermal effects, chemical phase evolution and lattice distortions [2,3,4]. Surface relaxation of stress also occurs during nitriding and is usually ascribed to a thermally controlled creep phenomenon and the diffusion of carbon (cementite precipitation) [5,6]. The carbon is released within the matrix during the transformation of initial carbides into nitrides [7,8,9]. However the creep assumption is not in good agreements with some experimental observations that were not able to analyse neither dislocations nor plastic strains through nitrided surfaces $[2,8]$. And the carbon assumption appears being incomplete since it does not take into account the transformation of carbides into nitrides. These assumptions of stress relaxation are also based on phenomenological approaches and thus are not reproducible to different kinds of nitrided steels.

This work aims so clarifying origins of stress relaxation during nitriding and estimating the role played by the diffusion of carbon and the transformation of initial carbides into nitrides. A model steel grade $\mathrm{Fe}-0.35 \% \mathrm{C}-3 \% \mathrm{Cr}$ is taken as a reference. 


\section{Modelling of nitriding}

The volume change calculation and mechanical modelling. A model is developed based on the diffusion of nitrogen and carbon. A volume change $(\Delta \mathrm{V} / \mathrm{V})_{\mathrm{P}}$ calculation was proposed in order to estimate the volumetric eigenstrain $\dot{\varepsilon}_{1 \cdot 0}$ generation accompanying the precipitation through the ferritic matrix [10]. It is based on Thermo-Calc calculations in order to estimate the chemical composition of each phase for given nitrogen and carbon contents within the nitrided surface and the comparison of the volume fraction of precipitates before $\left(y_{P}\right)$ and after $\left(y_{p}\right)$ nitriding. More details are given in [10]. Because the volume change of the ferritic matrix is assumed negligible compared to diffusion and precipitation, it comes for a given temperature $\mathrm{T}$ :

$$
\left.\frac{\Delta v}{v}\right|_{P}(T)=y_{P}(T) \cdot \frac{y_{P}^{\prime}(T) y_{F d}(T)-y_{P}(T) y_{F s}^{\prime}(T)}{y_{F}(T) \gamma_{F s}^{\prime}(T)}
$$

and

$$
\dot{\varepsilon}_{\text {vUt }}=\left.\dot{y}_{P}(T) \cdot \frac{1}{3} \cdot \frac{\Delta v}{v}\right|_{P}(T) \cdot I
$$

where $y_{\mathrm{w}, i}(T)=V_{\mathrm{i} i}(T) / V(T)$ is the volume fraction of phase $\phi_{t}$ at the temperature $T, \dot{y}_{\mathrm{r}}(\mathrm{T})$ the volume fraction rate of precipitates according to the transformations and $\boldsymbol{I}$ the second-order identity tensor.

The mean stress $\sigma_{, j}-\sigma_{y \dot{ }}$ in each phase (matrix and precipitates) as well as the macroscopic stress are then estimated using a mechanical model based on a self-consistent scheme and the calculation of the volume change accompanying the precipitation $[11,12]$.

Results. Experimental nitrogen and carbon content-depth profiles are presented on Fig. 1 in case of a model steel grade $\mathrm{Fe}-0.35 \% \mathrm{C}-3 \% \mathrm{Cr}$ [10]. A depletion of carbon, and respectively an enrichment, characterizes the compound-diffusion interface $(35 \mu \mathrm{m})$, respectively the nitrogen diffusion front $(400$ $\mu \mathrm{m})$. Fig. 2 shows the corresponding volume fraction gradient of each phase using Thermo-Cal software. A decrease of the cementite volume fraction is observed and corresponds to the depletion of carbon, whereas the enrichment of carbon results in an increase of initial carbide $\mathrm{M}_{7} \mathrm{C}_{3}$. Such results are also found in case of a $100 \mathrm{~h}$ nitriding and are in good agreements with experimental characterizations [10].

Fig. 3.a shows the volume change evolution accompanying the precipitation when taking into account the transformation of initial carbides into nitrides but also cementite (inter-granular carbides) or ferrite (intra-granular carbides) as observed experimentally [10]. A maximum of $2 \%$ is found. Fig. 3.b gives a comparison between the calculated mean residual stress $\sigma_{X X}-\sigma_{\mathrm{ZZ}}$ and X-ray diffraction analyses within the ferritic matrix. Both in-depth profiles are in good agreements. The transformation of initial carbides into nitrides but also into cementite and ferrite appears to be verified and non negligible.

Finally, the proposed model of nitriding gives no plastic straining of the model steel grade $\mathrm{Fe}-0.35 \% \mathrm{C}$ $3 \% \mathrm{Cr}$. Therefore compressive residual stresses are only due to the volumetric eigenstrain generation during the precipitation. 


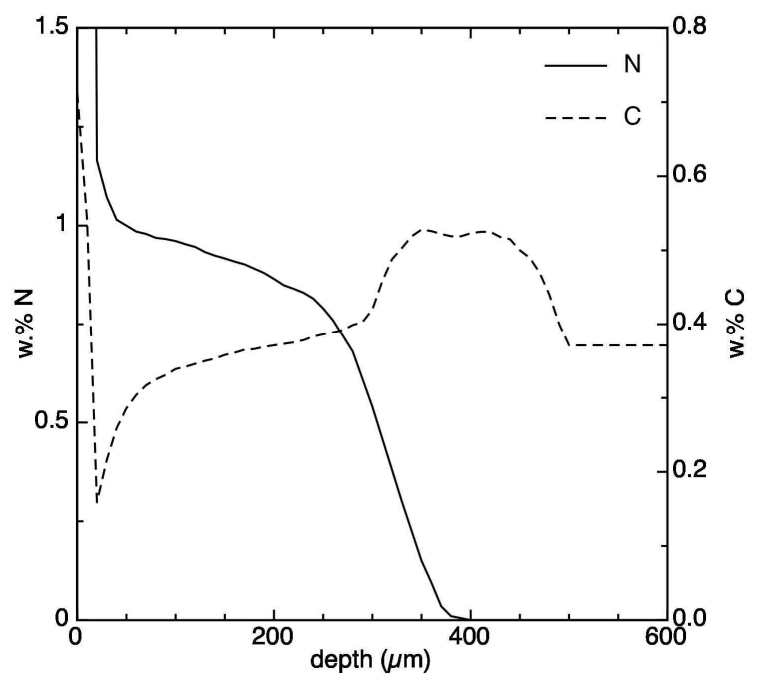

Fig. 1: Experimental nitrogen and carbon content-depth profiles obtained by EPMA and GDOES analyses [10].

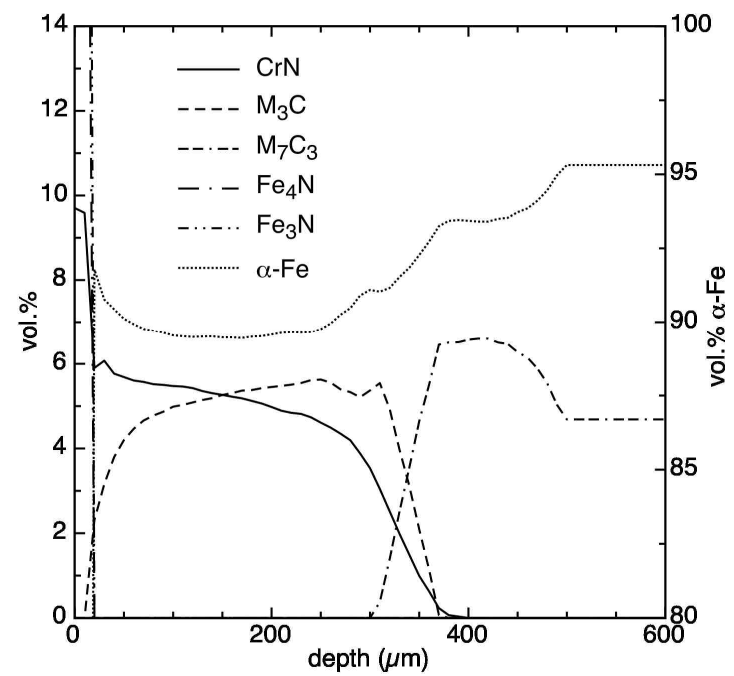

Fig. 2: Volume fraction-depth profiles of each phase. Thermo-Calc calculations.

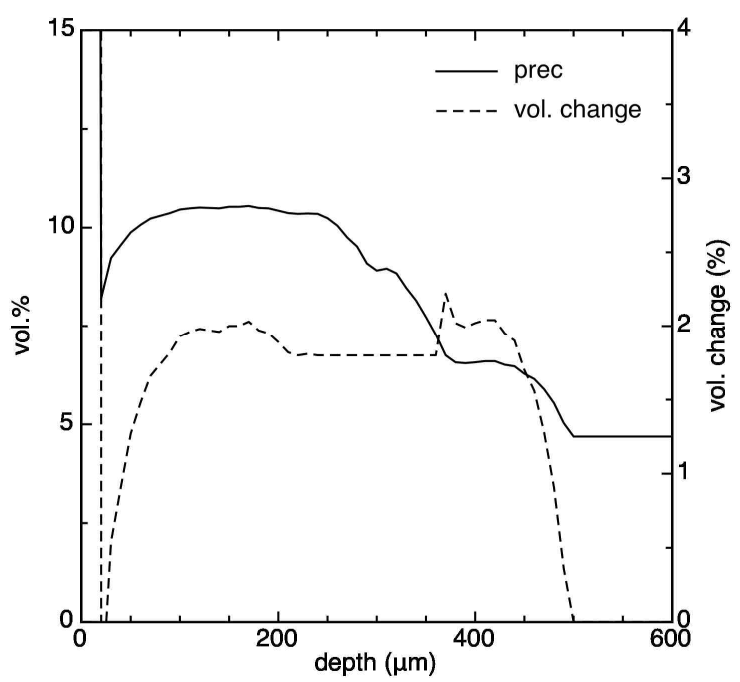

a.

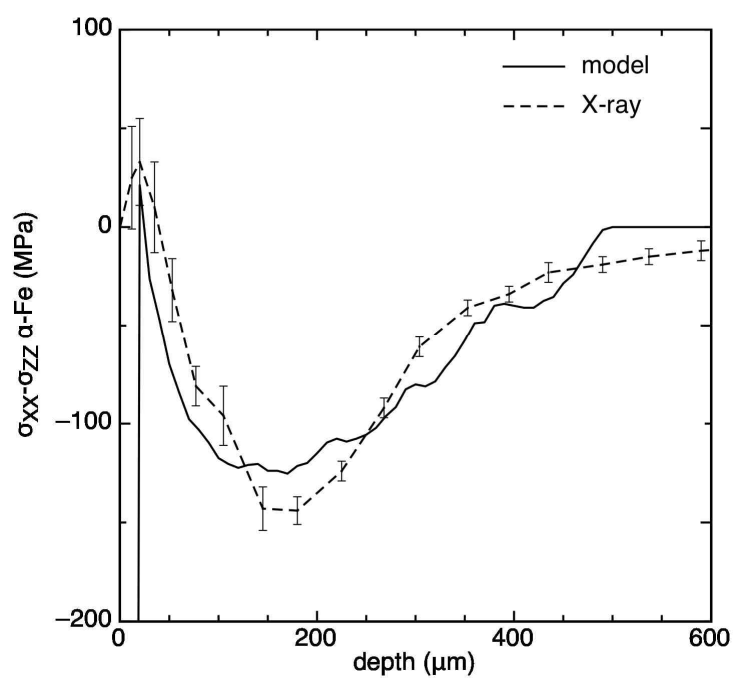

b.

Fig. 3: Evolution of (a) the global volume fraction of precipitates and the corresponding volume change, (b) the corresponding mean residual stress in the ferritic matrix compared to X-ray diffraction analyses $\left(\sin ^{2} \Psi\right.$ method). 


\section{Conclusions}

Residual stress find origins during nitriding through the volume change accompanying the precipitation of fine MN nitrides. Initial carbides are transformed into nitrides, but also into cementite and ferrite and counteract the precipitation of fine alloying elements nitrides from the ferritic solid solution. It results in a decrease of the compressive residual stress level. The diffusion of carbon involves also a volumetric unloading and stress relaxation of the nitrided surface. In the case of a model steel grade Fe$0.35 \% \mathrm{C}-3 \% \mathrm{Cr}$, no plastic straining is found to occur during nitriding.

\section{Acknowledgement}

This work was supported by Aubert \& Duval from the ERAMET Group, Snecma and Messier-Dowty from the SAFRAN Group.

\section{References}

[1] Totten G, Howes M, Inoue T: Handbook of residual stress and deformation of steel. Materials Park (OH): ASM International, 2002.

[2] Barrallier L, Barralis J: Proceedings of ICRS4, Baltimore, (MD) USA: Society for Experimental Mechanics Inc., 1994.

[3] Oettel H, Schreiber G: Proceedings of ICRS4, Baltimore, (MD) USA: Society for Experimental Mechanics Inc., 1994.

[4] Mittemeijer EJ: Proceedings of the symposium sponsored by the heat treatment committee of the metallurgical society of AIME held at the $112^{\text {th }}$ AIME annual meeting, Metallurgical Society of AIME, New-York, 1984.

[5] Oettel H, Schreiber G: Nitrieren und Nitrocarburieren, AWT, Wiesbaden, Germany, 1991.

[6] Buchhagen P, Bell T: Computational Materials Science, Vol 7, 1996, p. 228.

[7] Hirsch TK, Rocha ADS, Ramos FD, Strohaecker TR: Metallurgical and Materials Transactions A, Vol 35, 2004, p. 3523.

[8] Locquet JN, Barrallier L, Soto R, Charai A: Microscopy Microanalysis Microstructures, Vol 8, 1997, p. 335.

[9] Leroy C, Michel H, Gantois M: Journal of Materials Science, Vol 21, 1986, p.3467.

[10] Jegou S, Barrallier L, Kubler R: Acta Materialia, 2010.

[11] Jegou S, Kubler R, Barrallier L: Proceedings of the 2008 Denver X-ray Conference, Advances in X-ray Analysis, Vol 52, 2009.

[12] Jegou S, Kubler R, Barrallier L : Advanced Materials Research, Vol 89-91, 2010, p. 256. 